This item was submitted to Loughborough's Research Repository by the author.

Items in Figshare are protected by copyright, with all rights reserved, unless otherwise indicated.

\title{
Encapsulation application
}

PLEASE CITE THE PUBLISHED VERSION

http://www.springerreference.com/

PUBLISHER

(C) Springer

VERSION

AM (Accepted Manuscript)

LICENCE

CC BY-NC-ND 4.0

REPOSITORY RECORD

Vladisavljevic, Goran T.. 2012. “Encapsulation Application”. figshare. https://hdl.handle.net/2134/10607. 
This item was submitted to Loughborough's Institutional Repository (https://dspace.lboro.ac.uk/) by the author and is made available under the following Creative Commons Licence conditions.

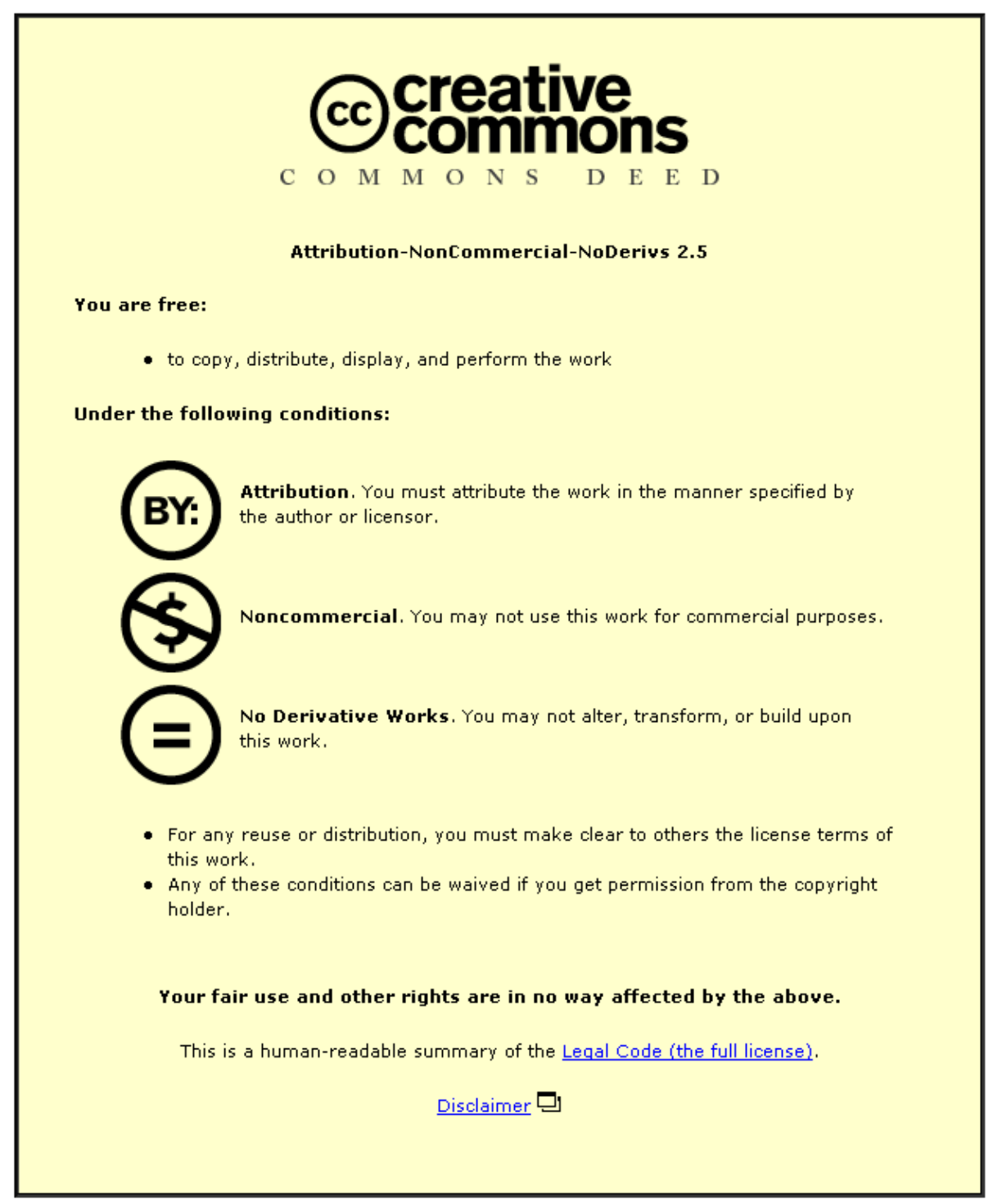

For the full text of this licence, please go to: http://creativecommons.org/licenses/by-nc-nd/2.5/ 


\title{
Encapsulation application
}

\author{
Goran T. Vladisavljević
}

Chemical Engineering Department, Loughborough University, Loughborough, Leicestershire, LE11 3TU, United Kingdom.

Microencapsulation can be done: (i) to protect the encapsulated material against oxidation or deactivation due to reactions with reactive species from the environment; (ii) to mask the organoleptic properties like color, taste, and odor of the actives; (iii) to achieve controlled/triggered/targeted release; (iv) for safe handling of toxic materials; (v) to achieve in vitro compartmentalization or immobilization of biological materials and catalysts.

Microencapsulated materials are utilized in agriculture, pharmaceuticals, foods, cosmetics and fragrances, textiles, paper, paints, coatings and adhesives, toner applications, and many other industries.

Carbonless copy paper developed by Green and Schleicher in the 1950s was the first commercial product to employ microcapsules. A coating of microencapsulated colorless ink is applied to the top sheet of paper, and a developer is applied to the subsequent sheet. When pressure is applied by writing, the capsules break and the ink reacts with the developer to produce the dark color of the copy. Paper-like displays with low power consumption such as rotating bichromal microspheres system and microencapsulated electrophoretic system are another example of commercial applications of microencapsulated ink (Yoshizawa 2004). In the rotating bichromal system (Gyricon), bichromal capsules with oppositely charged hemispheres are free to rotate within oil-filled cavities. In the microencapsulated electrophoretic display system (E ink), oppositely charged black and white particles move under an applied electric field in a clear liquid encapsulated within a transparent capsule.

Today's textile industry makes use of microencapsulated materials to enhance the properties of finished goods. One application increasingly utilized is the incorporation of microencapsulated phase change materials (PCMs), such as paraffin wax. Phase change materials absorb and release heat in response to changes in environmental temperatures. When temperatures rise, the phase change material melts, absorbing excess heat, and feels cool. Conversely, as temperatures fall, the PCM releases heat as it solidifies, and feels warm. Microencapsulation is also used in thermochromic and photochromic fabrics, which change 
color with changes in temperature or light, insect-repellent fabrics, which ward off mosquitoes, and scented fabrics, which release fragrance (Nelson 2002).

Pesticides are encapsulated to be released over time, allowing farmers to apply the pesticides less often rather than requiring very highly concentrated and perhaps toxic initial applications followed by repeated applications to combat the loss of efficacy due to leaching, evaporation, and degradation.

Ingredients in foods are encapsulated for several reasons (Gouin 2004). Most flavorings are volatile; therefore encapsulation of these components extends the shelf-life of products by retaining within the food flavors that would otherwise evaporate out and be lost. Some ingredients are encapsulated to mask taste, such as nutrients added to fortify a product without compromising the product's intended taste. Alternatively, flavors are sometimes encapsulated to last longer, as in chewing gum. Some food ingredients must be encapsulated to be protected from oxidation or other degradation reactions caused by exposure to light, moisture or oxygen. Microencapsulation preserves lactic acid bacteria, both starters and probiotics, in food and during the passage through the gastrointestinal tract, and may contribute to the development of new functional foods.

Many drug formulations for oral, intravenous, ocular and subcutaneous administration are microencapsulated to achieve controlled, targeted or triggered release of active ingredients. Aspirin, for example, can cause peptic ulcers and bleeding if doses are introduced all at once. Microencapsulation of cells and enzymes is used to improve efficiency of bioreactors since very high volumetric productivity can be achieved, encapsulated biocatalysts typically have greater thermal and operational stability and downstream processing is simplified, since the encapsulated biocatalyst can easily be recovered and reused. In molecular biology, singe-cell encapsulation is used to achieve high-throughput screening in directed evolution experiments.

\section{References:}

Gouin S (2004) Microencapsulation: industrial appraisal of existing technologies and trends. Trends Food Sci Technol 15:330-347.

Nelson G (2002) Application of microencapsulation in textiles. Int J Pharm 242:55-62.

Yoshizawa H (2004) Trends in microencapsulation research. KONA 22:23-31. 
